\title{
Event-related potentials and monoamines in autistic children on a clinical trial of fenfluramine
}

\author{
R.D. Oades ${ }^{1}$, L.M. Stern ${ }^{5}$, M.K. Walker ${ }^{3}$, C.R. Clark ${ }^{4}$ and V. Kapoor ${ }^{2}$ \\ ${ }^{I}$ Department of Physiology, ${ }^{2}$ Department of Medicine, ${ }^{3}$ Department of Psychiatry, ${ }^{4}$ Depariment of Psychology, \\ Flinders Medical Centre, Bedford Park, (Australia) and ${ }^{5}$ Regency Park Centre for Young Disabled, Regency Park, (Australia)
}

(Accepted 16 November 1988)

Key words: Autism; Event-related potential; Fenfluramine; Serotonin; Noradrenaline; Dopamine; Homovanillic acid; Attention

In a double blind, crossover study of the response of autistic subjects to fenfluramine, event-related potentials (ERPs) were recorded from 7 subjects on an attention-demanding auditory choice reaction time task (ACRT). ACRT, IQ and biochemical measures were taken after 5 months placebo and 5 months fenfluramine treatment. After fenfluramine treatment blood serotonin levels fell, urinary catecholamine levels fell and the HVA/DA ratio rose. IQ and ACRT performance improved. On the ACRT subjects were asked to press a button to a rare target $(500 \mathrm{~Hz}, P=0.14)$ and to ignore higher pitched rare $(2000 \mathrm{~Hz}, P=0.14)$ and frequent non-targets $(1000 \mathrm{~Hz})$. After fenfluramine treatment N1 latencies increased. The scalp distribution of ERP maxima changes slightly with treatment. P3 maxima elicited by rare non-targets were recorded more rostrally after fenfluramine treatment. After rare non-targets $\mathrm{N} 1$ amplitudes at $\mathrm{Fz}$ decreased but $\mathrm{P} 3$ amplitudes at $\mathrm{Pz}$ increased. Early negativity after the rare non-target (particularly on the right side) was negatively correlated with the HVA/DA ratio. Subtraction of the $\mathrm{P} 3$ component elicited in a passive condition where no response was required from the active condition showed that $\mathrm{P} 3$ positivity to targets was halved with treatment. (In contrast Nd increased on fenfluramine treatment). Overall, N1 and P3 components showed greatest responsivenes to rare non-targets on fenfluramine. N1 but not P3 changes may represent slight improvement of attention-related function with treatment. Small changes in ERP latency and distribution, associated with the neuroleptic action of fenfluramine may be partly responsible for a mild improvement of IQ and ACRT performance on medication.

\section{INTRODUCTION}

In childhood autism there are disturbances in social relating, communication, language, response to objects, sensory modulation and motility (Ornitz, 1985). Although 75\% of autistic children may be mentally retarded, they are usually not impaired in visuo-spatial or perceptual skills (Kanner, 1943; Rutter, 1983). But they do have difficulty in learning and discrimination tasks

Correspondence: R.D. Oades. Present address: Klinik f. Kinderu. Jugendpsychiatrie, Hufelandstr. 55, D-4300 Essen 1, F.R.G.
(Frankel et al., 1984; Miyashita, 1985) and in selecting and encoding meaningful stimuli (Hermelin and O'Connor, 1970). Thus current research emphasizes an attentional dysfunction in autism (Damasio, 1984).

A recent multi-centre study (Ritvo et al., 1983; 1986) found that fenfluramine elicited mild behavioral improvement in some subjects. Improvement may be more prominent in children with higher IQs (Stubbs et al., 1986; Campbell et al., 1986; but not Campbell et al., 1987). Yet it is seldom that fenfluramine treatment changes global measures of IQ (August et al., 1984). Rather, improvement is found on specific measures (e.g. of attention; digit span, Ho et al., 1986). 
Let us consider first the effect of fenfluramine on allention-related function, as shown by study of event-related potentials (ERPs), and second its effect on neurotransmitter activity.

\section{ERP studies}

The amplitude of a stimulus-elicited early negative ERP component (N1), usually maximal at frontal sites, increases in response to rare deviant stimuli (Hink et al., 1978). It is claimed to reflect, in part, an early stage of selective attention (Hansen and Hillyard, 1980). The amplitude of a later positive P3 component, often maximal at parietal sites, varies with the probability of occurrence of a task-relevant event (Duncan-Johnson and Donchin, 1977). P3 latency increases with taskdifficulty, often covarying with reaction time (McCarthy and Donchin, 1981; Ford et al., 1982).

With respect to adults children show longer ERP latencies (Goodin et al., 1978; Halliday et al., 1984). Autistic and psychotic children are reported to show auditory and visual FRPs (inc. P1, N1, P2 and P3) with shorter latencies than healthy children (Small et al., 1971; Saletu et al., 1975; Martineau et al., 1984a; not Courchesne et al., 1984; 1985). ERPs in children are often smaller than in adults. On a variety of auditory tasks ERPs in autistic subjects, (particularly N1 and P3 amplitudes, but not always both), have been found to be smaller than in age-matched controls (Small et al., 1969; 1971; Ornitz et al., 1972; Lelord et al., 1973; Novick et al., 1980; Martineau et al., 1984b; Niwa et al., 1983; Courchesne et al., 1984; 1985).

In a two-tone auditory discrimination, frequent non-target tones were found to elicit larger N1-P3 amplitude differences at the vertex in autistic than normal children. Fenfluramine treatment reduced this increase (August et al., 1984). The first purpose of our study was to extend these results by separately recording ERPs (a) from 3 midline and 4 lateral sites and (b) in a task situation where the information load clearly places demands on selective attention abilities (cf. Damasio, 1980, above). In such a task subjects discriminate rare target from rare and frequent (standard) non-target tones presented rapidly in sequence (Pfefferbaum et al., 1984).

\section{Biochemical studies}

Ritvo et al. (1986) reported that fenfluramine reduced high blood serotonin (5-HT) levels in autistic children. Fenfluramine reduces central levels of 5-HT and its metabolite 5-hydroxyindoleacetic acid (5-HIAA). The (+)-enantiomer shows anorectic properties, promotes the release and inhibits the re-uptake of 5-HT at clinically relevant doses (Rowland and Carlton, 1986; Invernizzi et al., 1986).

High levels of 5-HT in blood have been consistently reported over the last 25 years (Schain and Freedman, 1961) for many (Hoshino et al., 1984) but not all subjects diagnosed autistic (Ho et al., 1986) or mentally retarded (Cohen et al., 1977). There are conflicting reports on changes in the noradrenaline (NA) system of autistic children (review, Young et al., 1982). Decreased urinary levels of free NA and the metabolite MHPG have been found. But plasma and CSF MHPG are reported unchanged. Increases and decreases of the synthesizing enzyme $\mathrm{DBH}$ are reported in autistic and psychotic children. In general it would appear that NA synthesis and breakdown is decreased in autism.

The (-)-isomer of fenfluramine has dopamine (DA) antagonist properties (Rowland and Carlton, 1986; Invernizzi et al., 1986). Urinary excretion of the DA metabolite homovanillic acid (HVA) was reported to be high in autistic subjects (Martineau et al., 1984b; Garnier et al., 1986). Cohen et al. (1977) found CSF levels of HVA and 5-HIAA were correlated in autistic and psychotic children (0.62 and 0.77 respectively). CSF-HVA levels were not elevated in autistic subjects as a group, but were higher in those with more severe motor and stereotypy problems (Young et al., 1982). Gillberg and Svennerholm (1987) reported markedly increased CSF-HVA levels and larger HVA/MHPG ratios. The second purpose of this study was to compare urinary levels of NA, DA and HVA at the end of placebo and fenfluramine treatments and see if these correlated with ERP task-related variables measured at the same time.

This report is part of a larger placebo-controlled, double-blind, crossover study of the efficacy of treatment of autistic children with racemic fenfluramine. Reports on blood levels of 
fenfluramine, 5-HT and other measures of cognitive, language and social behavior are published separately (Badcock et al., 1987; Stern et al., in press).

\section{METHODS}

\section{Subjects}

From the original 20 autistic subjects (DSM III) of the clinical trial, only 7 understood the task and provided sufficient artifact-free recordings. All preferred to use their right hand (6 male, one female: age range, 5.8 to 17.7 years (mean $11.3 \mathrm{y}$, S.D. 4.0)). Reports from subjects and/or their parents indicated that hearing was normal. This was confirmed by pure tone audiometry in some, but in others who were non-compliant, hearing was estimated to be normal after impedance audiometry and vocabulary tests showed no peripheral hearing losses.

\section{General procedure}

Children and their parents or guardians visited the laboratory in the last month of each 5-month counterbalanced placebo and fenfluramine period. Before crossover all subjects received placebo for two months. Investigators and subjects were blind to the treatment condition. A familiarization visit was followed by another on which ERPs were recorded. Data were recorded within a week of psychological testing and urine collection. During auditory choice reaction time task (ACRT) presentation subjects sat in a sound-attenuated room under subdued lighting with their eyes open and were asked to fixate a point in front of them.

\section{ACRT and intelligence tests}

In the ACRT (Pfefferbaum et al., 1984), pure sinusoidal tones $(500 \mathrm{~Hz}, P<0.14 ; 1000 \mathrm{~Hz}, P<$ $0.72 ; 2000 \mathrm{~Hz}, P<0.14)$ were played through Telephonics earphones (TDH-49P) at $50 \mathrm{dBSL}$ (SL default value $20 \mathrm{~dB}$ ) against a background of white noise at $20 \mathrm{~dB}$ above threshold (intertrial interval, minimum 500, maximum $1300 \mathrm{~ms}$ ) in a computer-generated pseudo-random order. The two rare tones could not occur in succession. The tones lasted $80 \mathrm{~ms}$, excluding a $10 \mathrm{~ms}$ rise and 10 ms fall time.

Tones were presented in 140-trial blocks (ca. 4 min) in passive and active conditions. In the passive condition subjects were asked to listen to the tones and keep still. In the active condition subjects were asked to press a button on a response panel to each low tone $(n=20)$. A pressure of 100 $\mathrm{g}$ on the button operated a microswitch. In addition to the ERP, the reaction time, errors of omission and commission, the number of trials accepted and those rejected through artifact, slow or fast responses were recorded.

Usually three active trial blocks were presented with short rest pauses between. Three subjects required an extra session to increase the number of accepted target trials above 10. Training and practice was required between the first passive and the active blocks. In the instructions emphasis was placed on keeping still, accuracy and speed.

IQ was rated on the Leiter or non-verbal components of the British Ability Scales for subjects over 15 years. These scales were chosen to avoid confounding with practice effects likely with other scales commonly used in South Australia. The tests were performed by the subjects at home in the last two weeks of each treatment condition.

\section{Data acquisition and recording procedures}

EEG activity was recorded with an electrode cap (ACI, Electrocap International) from tin electrodes located in midline frontal $(\mathrm{Fz})$, central $(\mathrm{Cs})$ and parietal $(\mathrm{Pz})$ and from lateral sites $\left(\mathrm{F}_{3}, \mathrm{~F}_{4}, \mathrm{P}_{3}\right.$, $\mathrm{P}_{4}$ ). Subjects were grounded with an electrode on the forehead and activity referenced to linked earlobes. A similarly referenced vertical electrooculogram was recorded from an electrode close to the supraorbital ridge of the right eye. Electrode impedances were never above $6 \mathrm{k} \Omega$ and usually half that value.

P511 K Grass amplifiers with an upper and lower half-amplitude cut-off of 30 and $0.01 \mathrm{~Hz}$. respectively, and a $50-\mathrm{Hz}$ notch filter were used at an EEG amplification of $5 \times 10^{4}$ (EOG, $5 \times 10^{3}$ ). Data, managed on-line by a LSI $11 / 73$ computer, were digitized at a sample rate of $1 \mathrm{~ms}$ for $1 \mathrm{~s}$ beginning $100 \mathrm{~ms}$ before stimulus onset. Trials in which the EEG was contaminated by movement 
artifact were eliminated if one in ten samples exceeded a threshold of $\pm 90 \mu \mathrm{V}$.

\section{Data analysis}

All peak measures were computed from voltages averaged with respect to the $100-\mathrm{ms}$ prestimulus epoch for each tone-stimulus condition separately. Averaged ERP waveforms were digitally filtered (triangular filter: $-3 \mathrm{~dB}$ at $15 \mathrm{~Hz}$, half amplitude $21 \mathrm{~Hz}$ ). N1 peak negativity or $\mathrm{P} 2$, P3, P4 positivity was sought in the following windows (ms, post-stimulus): N1, 120-240; P2, 150-300; P3, 300-600; P4, 600-900. P3 was taken as the earlier more positive wave in the $\mathrm{P} 3$ or $\mathrm{P} 4$ window. SW positivity, subsequent to $\mathrm{P} 3$ identification, was sought in the $650-900 \mathrm{~ms}$ window. Difference wave forms were obtained firstly by subtracting components elicited by the target and non-target in the active condition and secondly by subtracting the components elicited by the same 'target tone' in the active and passive conditions (cf. Hansen and Hillyard, 1980). The average negativity on the first $400 \mathrm{~ms}$ (NW) was taken as a putative indicator of arousal (Bjorn et al., 1986).

After recording the topographic distribution of maximum averaged $\mathrm{N} 1$ and $\mathrm{P} 3$ waves for individual subjects, grand mean data were analysed at $\mathrm{Fz}$ and $\mathrm{Pz}$ sites respectively. Unless otherwise stated repeated measures analyses of covariance were performed for 7 subjects. Chronological age was used as a covariate as it was found that after removal of the blind our subgroup of subjects was not counter-balanced on this factor as in the autistic group as a whole. Initially a 3-way MANOVA on the midline ERP data was performed (2 treatment, 3 tone conditions and 3 recording sites). Subsequently in view of missing data. in some cases reducing the number of subjects to 5, 2-way MANOVAs ( 2 treatment and 3 tone conditions) were also carried out. Significant results for N1, NW, P3 and SW latencies and peak amplitudes were followed by post-hoc Tukey tests.

Difference waveforms (T-'T', T-NT, NT-standard) were individually examined by one-way analysis of variance on the effect of treatment. The amplitude of ERPs from lateral sites was simularly analysed before and after scaling of the voltage values (see McCarthy and Wood, 1985).
Biochemical, behavioral and derived measures were analysed by paired $t$-test for related samples; (one-tailed tests were used only for biochemical measures where the effect of fenfluramine was predicted from its known pharmacological effects). Taking age into account Pearson partial correlation coefficients for variation of DA and its metabolism with ERP and performance measures were calculated (cf. results and Table IV).

\section{Biochemical analysis}

Urine $(24 \mathrm{~h})$ was collected in acid ( $\mathrm{pH} 2)$ in the last month of each treatment period within $48 \mathrm{~h}$ of recording ERPs. The volume was measured and $100 \mathrm{ml}$ samples frozen at $-80^{\circ} \mathrm{C}$. Separate analyses were run for (1) NA and DA and (2) HVA with HPLC and electrochemical detection. NA and DA were separated by an organic phase extraction (Smedes et al., 1982) and run in a mobile phase of phosphate buffer ( $\mathrm{pH} \mathrm{4.2)}$, sodium octyl sulphonic acid $(0.7 \mathrm{mM})$ and $10 \%(\mathrm{v} / \mathrm{v})$ methanol, (inter/intra-assay variation $<6 \%$ and $<8 \%$, respectively). HVA was extracted from Dowex AG1 columns eluted with $10 \mathrm{ml} 3 \mathrm{M}$ sodium chloride and run in phosphate buffer $(\mathrm{pH}$ 3.9) with $0.1 \mathrm{mM}$ sodium octyl sulfonic acid and 14\% (v/v) methanol (Soldin, 1982; inter/intraassay variation $<10 \%$ and $<11 \%$ ). Data are presented per mg creatinine and corrected for subject body area, calculated as a function of height and body mass.

In the placebo period $14 / 20$ subjects, but in both the placebo and fenfluramine periods only 11 provided urine. Six of these were also subjects with ERP data (cf. ERP-biochemical correlations).

\section{RESULTS}

\section{Urine analysis}

In the 5-10-year age group there were 8 and in the 10-19-year age group there were 6 autistic subjects who provided samples in the placebo condition. Whereas the mean of $33.3 \mathrm{mg} / \mathrm{g}$ creatinine for the older group is comparable with lcvels for normal children of $44.2 \mathrm{mg} / \mathrm{g}(n-55$; Soldin, 1982), levels in the younger group of 66.1 
TABLE I

Individual and behavioral data in the placebo and fenfluramine condition

${ }^{1}$ Leiter scale; ${ }^{2}$ estimate from British Ability Scale; ${ }^{3}$ proportion of trials rejected for movement artifact; ${ }^{4}$ behavioral data calculated independently of movement artifact.

\begin{tabular}{|c|c|c|c|c|c|c|}
\hline $\begin{array}{l}\text { Condition } \\
+ \text { subject }\end{array}$ & $\begin{array}{l}\text { Chronological } \\
\text { age (months) }\end{array}$ & $\begin{array}{l}\text { Mental age } \\
\text { (months) }^{\prime}\end{array}$ & $\begin{array}{l}\text { Reaction } \\
\text { Time (ms) }\end{array}$ & $\begin{array}{l}\text { Movement } \\
(\% \text { reject })^{3}\end{array}$ & $\begin{array}{l}\text { Errors } \\
\text { omission }^{4}\end{array}$ & $\begin{array}{l}\text { Criterion } \\
\text { (beta) }\end{array}$ \\
\hline \multicolumn{7}{|l|}{ Placebo } \\
\hline Subject 1 & 212 & $191^{2}$ & 422 & 61 & 7 & 11.5 \\
\hline 2 & 69 & 69 & 526 & 18 & 80 & 23.4 \\
\hline 3 & 96 & 151 & 677 & 65 & 23 & 7.8 \\
\hline 4 & 141 & 123 & 608 & 32 & 63 & 15.9 \\
\hline 5 & 116 & 106 & 616 & 29 & 8 & 6.6 \\
\hline 6 & 177 & 156 & 576 & 24 & 10 & 6.6 \\
\hline 7 & 139 & 65 & 456 & 23 & 63 & 11.7 \\
\hline mean/median & 136,139 & 123,123 & 557,576 & 36,29 & 36,23 & $11.9,11.5$ \\
\hline \multicolumn{7}{|l|}{ Fenfluramine } \\
\hline Subject 1 & 218 & $202^{2}$ & 564 & 43 & 3 & 6.1 \\
\hline 2 & 62 & 51 & 609 & 28 & 64 & 14.0 \\
\hline 3 & 102. & 135 & 645 & 68 & 13 & 6.9 \\
\hline 4 & 147 & 139 & 636 & 28 & 38 & 9.5 \\
\hline 5 & 123 & 118 & 650 & 34 & 0 & 6.0 \\
\hline 6 & 183 & 176 & 501 & 17 & 3 & 6.2 \\
\hline 7 & 132 & 67 & 545 & 26 & 64 & 11.4 \\
\hline mean/median & 138,132 & 127,135 & 593,609 & 35,28 & $26 *, 13$ & $8.6^{*}, 6.9$ \\
\hline
\end{tabular}

* $P<0.05$ (see text).

are twice the value of 33.2 reported for normal children $(n=79)$.

Of the 11 subjects providing two urine samples, 5 were unable to perform the ERP part of the study. For these 5 there were no significant changes of NA, DA or HVA between treatments. In the fenfluramine period the other 6 subjects (in the ERP study) showed $45 \%$ less NA $(t=-3.4, P<$ 0.02 ), a $25 \%$ drop of DA and increased HVA (224\%) excretion (Table I). There was an increase of over $600 \%$ in DA metabolic activity shown by the metabolite/transmitter ratio $(t=-1.9, P<$

\section{TABLE II}

Levels of noradrenaline (NA), dopamine (DA), homovanillic acid (HVA) and DA utilization (HVA/DA) in $24 \mathrm{~h}$.

Urine samples collected at the end of placebo $(\mathrm{P})$ and fenfluramine $(\mathrm{F})$ trial periods for autistic children $\left(\mathrm{mg} / \mathrm{g} . \mathrm{creatine} / \mathrm{m}^{2}\right)$. Sample ( $n$ 11) compared with sample $(n$ ) for which ERP data available, with chronological and mental ages (Leiter scale).

\begin{tabular}{|c|c|c|c|c|c|c|c|c|c|c|c|c|}
\hline & \multicolumn{2}{|c|}{$N A(S . E . M)}$. & \multicolumn{2}{|c|}{$D A(S . E . M)}$. & \multicolumn{2}{|c|}{$H V A(S . E . M)}$. & \multicolumn{2}{|c|}{$H V A / D A(S . E . M)}$. & \multicolumn{4}{|c|}{$\begin{array}{l}\text { Chronological IQ (mean) } \\
\text { months (mean) Leiter scale }\end{array}$} \\
\hline & $n .11$ & $n 6$ & $n 11$ & $n 6$ & $n 11$ & n6 & $n l l$ & $n 6$ & $\overline{n I I}$ & $n 6$ & $n 11$ & $n 6$ \\
\hline $\bar{P}$ & $\begin{array}{l}37.0 \\
(4.0)\end{array}$ & $\begin{array}{l}38.4 \\
(5.6)\end{array}$ & $\begin{array}{l}497.8 \\
(79.0)\end{array}$ & $\begin{array}{l}477.8 \\
(136)\end{array}$ & $\begin{array}{c}48.4 \\
(11.6)\end{array}$ & $\begin{array}{c}36.7 \\
(11.4)\end{array}$ & $\begin{array}{c}0.104 \\
(0.023)\end{array}$ & $\begin{array}{c}0.082 \\
(0.025)\end{array}$ & 119 & 129 & $\begin{array}{l}78.4 \\
(8.8)\end{array}$ & $\begin{array}{c}87 \\
(15.4)\end{array}$ \\
\hline$F$ & $\begin{array}{l}26.3 \\
(4.6)\end{array}$ & $\begin{array}{l}20.8 * \\
(5.7)\end{array}$ & $\begin{array}{l}422.1 \\
(89.7)\end{array}$ & $\begin{array}{l}353.6 \\
(123)\end{array}$ & $\begin{array}{l}58.1 \\
(9.1)\end{array}$ & $\begin{array}{l}54.7^{*} \\
(11.9)\end{array}$ & $\begin{array}{l}0.258 * \\
(0.072)\end{array}$ & $\begin{array}{l}0.339 * \\
(0.122)\end{array}$ & 119 & 130 & $\begin{array}{c}81.9 \\
(10.2)\end{array}$ & $\begin{array}{l}96 \\
(15.9)\end{array}$ \\
\hline $\begin{array}{l}F \text { as } \\
\% P\end{array}$ & $\begin{array}{c}72.2 \\
(11.2)\end{array}$ & $\begin{array}{c}55.0 \\
(15.1)\end{array}$ & $\begin{array}{c}85.0 \\
(17.8)\end{array}$ & $\begin{array}{l}75.0 \\
(27)\end{array}$ & $\begin{array}{l}188.2 \\
(42.8)\end{array}$ & $\begin{array}{l}224.3 \\
(54.2)\end{array}$ & $\begin{array}{c}403.3 \\
(139.2)\end{array}$ & $\begin{array}{c}603.2 \\
(227.2)\end{array}$ & & & & \\
\hline
\end{tabular}

${ }^{*} P<0.05$. 

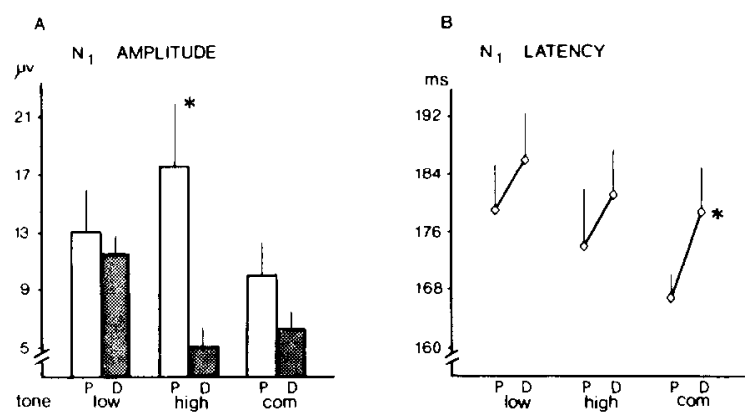

Fig. 1. A: N1 amplitude (S.E.M., $\mu \mathrm{V}$ ) at Fz elicited by low (target), high (rare non-target) and standard (common nontarget) tones in the placebo ( $\mathrm{P}$, open bars) and fenfluramine condition (D, hatched bars). B: N1 peak latency (S.E.M., ms) at $\mathrm{Fz}$ after target, rare and common tones, ${ }^{*} P<0.05$.

$0.05)$. This correlated negatively with NA levels $(-0.74, P<0.04)$. HVA is the main DA metabolite in man (Kopin, 1985). The metabolite/ transmitter ratio also may be used as an indirect index of utilization (Roth et al., 1976; Algeri et al., 1987), assuming that fenfluramine did not alter the efflux of transmitter or metabolite and alter the proportion of centrally derived substances in the urine (Westerink and Kikkert, 1986).

\section{Task performance}

The proportion of data rejected due to movement artifact did not differ between conditions. Reaction time increased by a mean of $71 \mathrm{~ms}$ for 5 subjects in the fenfluramine condition (Table I), but for the group of 7 there was a non-significant increase of only $6.5 \%$.
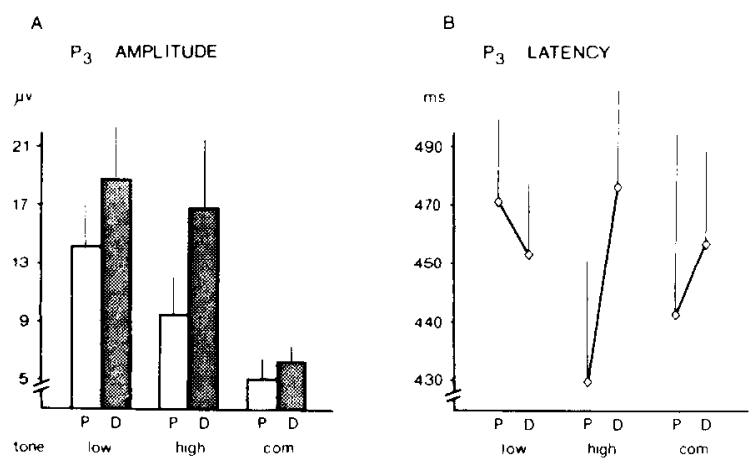

Fig. 2. A: P3 amplitude (S.E.M., $\mu$ V) elicited by low (target), high (rare non-target) and standard (common non-target) tones in the placebo ( $\mathrm{P}$, open columns) and fenfluramine condition (D, hatched columns). B: P3 peak latency (S.E.M., ms) after target, rare and common tones.

Were subjects able to perform the task more successfully in the fenfluramine period? There were too few errors of commission to warrant a separate analysis, but errors of omission decreased $(27 \%)$. Signal detection measures of sensitivity $\left(d^{\prime}\right)$ showed no changes but measures of criterion (beta) decreased significantly $(t=2.4, \quad P<0.05$; Table I). IQ measures increased on average 7.5 points in the fenfluramine condition for subjects providing ERP data $(t,-3.4, P<0.02$; Table II). Irrespective of treatment there were trends for a negative association of DA level with IQ and reaction time (both $-0.64, P<0.08$ ) and a positive association with measures of criterion $(0.62, P<0.09)$.

\section{TABLE III}

Changes of midline sites for NI and P3 maximum amplitudes with stimulus (target, non-target and standard), placebo and fenfluramine treatment.

Data are numbers of subjects with maxima at $\mathrm{Fz}, \mathrm{Cz}, \mathrm{Pz}$ to rare and standard tones.

\begin{tabular}{|c|c|c|c|c|c|c|c|c|c|}
\hline & \multicolumn{3}{|c|}{ Target } & \multicolumn{3}{|c|}{ Non-Target } & \multicolumn{3}{|c|}{ Standard } \\
\hline & $\overline{F z}$ & $C z$ & $\overline{P_{z}}$ & $\overline{F z}$ & $C z$ & $P \overline{P_{z}}$ & $F z$ & $C z$ & $\overline{P z}$ \\
\hline \multicolumn{10}{|l|}{$\overline{N 1}$} \\
\hline Placebo & 4 & 3 & 0 & 4 & 0 & 3 & 3 & 2 & 2 \\
\hline Fenfluramine & 3 & 2 & 2 & 1 & 2 & 4 & 3 & 3 & 1 \\
\hline \multicolumn{10}{|l|}{ P3 } \\
\hline Placebo & 3 & 2 & 2 & - & 2 & 5 & 2 & 2 & 3 \\
\hline Fenfluramine & 1 & 3 & 3 & 2 & 3 & 2 & 1 & 3 & 3 \\
\hline
\end{tabular}


Bi Placelo

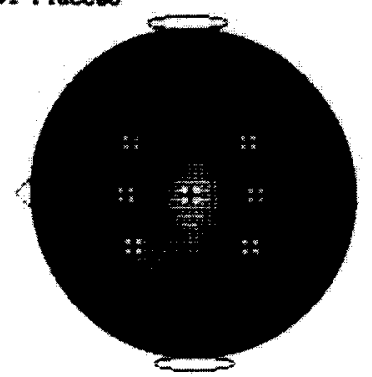

84: P3: 594 is

D1 Placebo

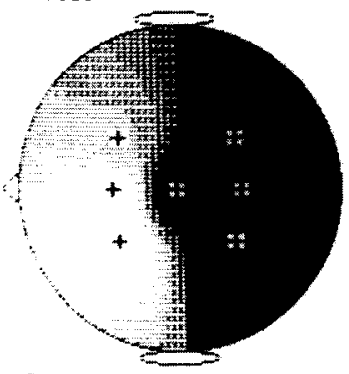

23; P3; $744 \mathrm{~ms}$

F1 Placebo

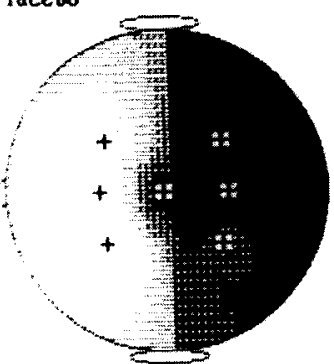

6n: P3; 152 ns

H1 Placebo

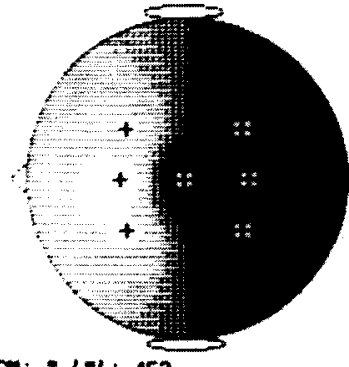

G: 1-'T': $452 \mathrm{~ms}$

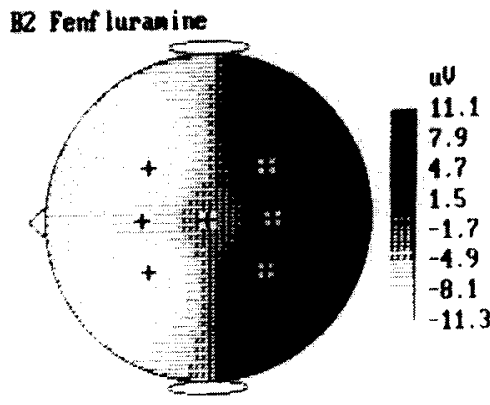

64: P3: $519 \mathrm{~ms}$

D2 Fenf luranine

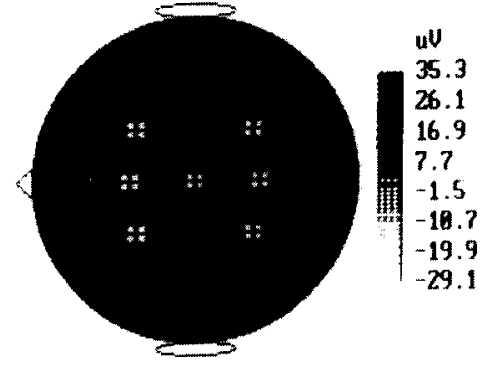

63: P3: 537 us

F2 Penf luramine

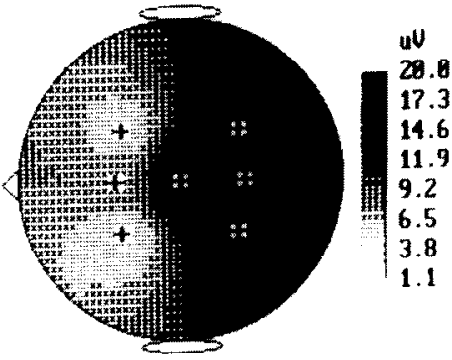

G1: P3: 427 ms

H2 Fenfluranine

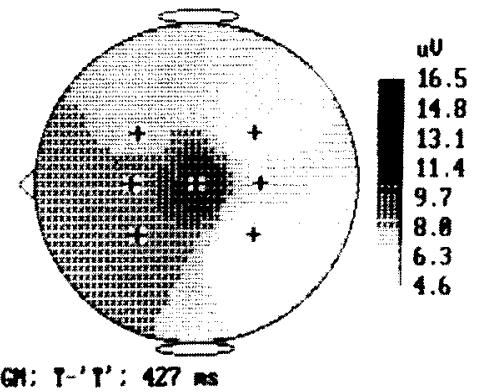

Fig. 3. For legend see p. 205. 


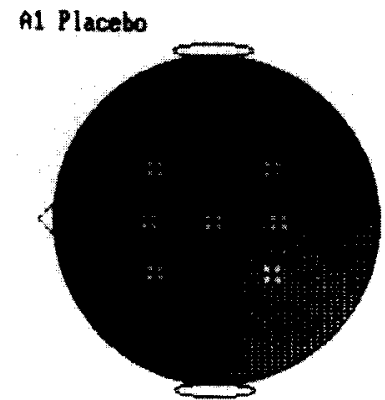

64: M1: 171 แ

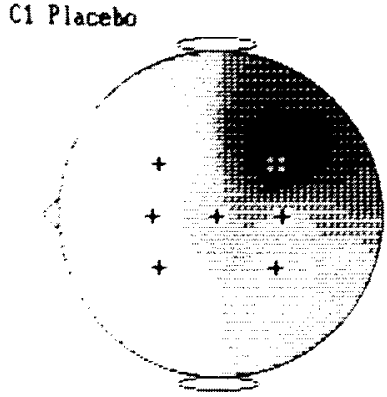

83: 11; 205 us

I1 Placebo

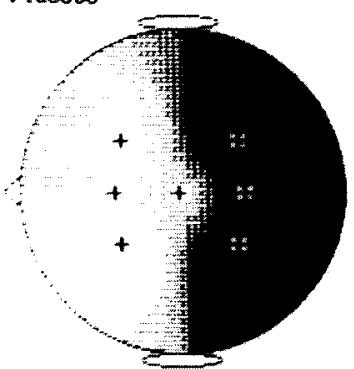

G: N1: 178 us

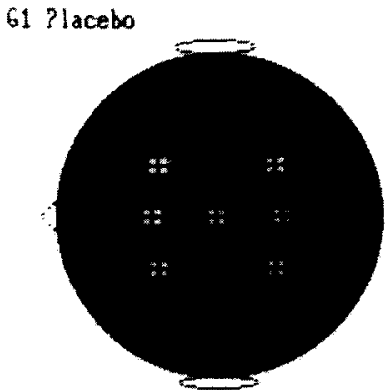

G: I' $I^{\prime} ; 178$ us
A2 Fenf luranine

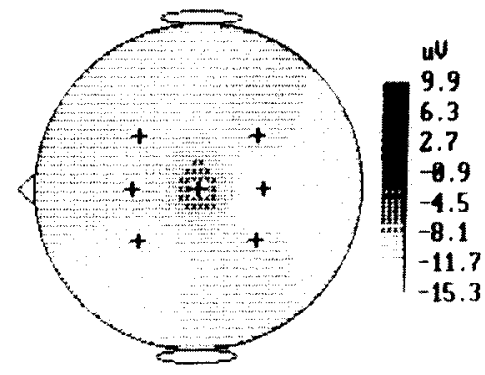

84: N1; 182 ms

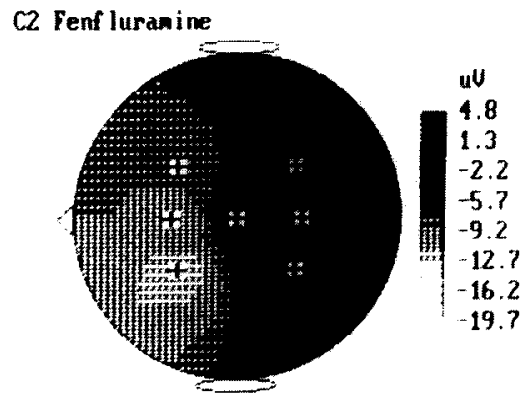

63: $\mathrm{M1}: 173 \mathrm{~ms}$

12 Fenf luramine

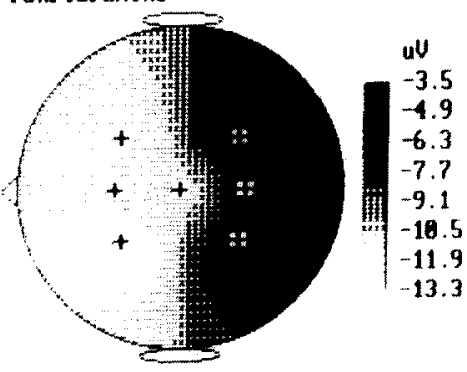

G): N1: $186 \mathrm{~ms}$

62 Fenf luranine

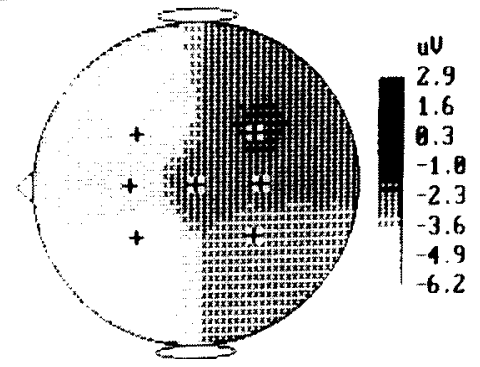

G) 1-'T': 186 ms 


\section{Distribution of midline ERP maxima}

Recording sites where $\mathrm{N} 1$ and $\mathrm{P} 3$ components were maximal showed a variable rostrocaudal distribution in placebo and fenfluramine periods (Table III). To standards N1 and P3 maxima were relatively more rostrally and caudally distributed (respectively) in both treatment conditions. With fenfluramine frontal $\mathrm{N} 1$ maxima to both rare stimuli moved one or two recording sites caudally. This was significant for the rare non-target where only one rostral change was recorded (Fisher test, $P<0.05$; e.g. subject $04, \mathrm{Cz}$ to $\mathrm{Pz}$, Fig. $3 \mathrm{~A}$ ). On placebo $\mathrm{P} 3$ maxima after rare non-targets were evident at caudal sites. In the fenfluramine condition, while non-target $\mathrm{P} 3$ maxima tended to move rostrally (to $\mathrm{Fz} / \mathrm{Cz}$ ), target $\mathbf{P} 3$ maxima tended to move caudally (to $\mathrm{Cz} / \mathrm{Pz}$; e.g. subject 04 , Fig. $3 \mathrm{~B}$ ). With one site-movement in the opposite direction in each case this is also significant at the $5 \%$ level on the assumption that $\mathrm{N} 1 / \mathrm{P} 3$ and target/nontarget measures were independent (Table 3: cf. 7 sites in 3-way MANOVA, below).

\section{Midline ERPs}

The acceptance rate for ERP data elicited by target stimuli ranged from 30 to $38 \%$ on placebo and fenfluramine conditions, respectively (mean number of target trials analysed (S.E.M.): placebo, 27 (7); fenfluramine condition $30(7)$ ).

NI latency. There was no main effect of treatment $(\mathrm{df}=1,5 ; F=2.5 ; P=0.1)$. Yet latencies at $\mathrm{Fz}$ were longer on fenfluramine for most subjects (for 6 to targets, for 7 to standards, for 5 to rare non-targets; $P 0.02>0.05$, Wilcoxon, Fig. 1).

NI amplitude. Taking into account that N1 co-varied with age $(\mathrm{df}=1,5 ; \quad F=8.5 ; \quad P=0.03)$, there was a 3 -way interaction $(\mathrm{df}=4,24 ; F=2.7$, $P=0.05)$. Site made a minor contribution to the interaction $(\mathrm{df}=2,12, F=2.1, P=0.1)$, but there was a significant treatment-stimulus interaction $(\mathrm{df}=2,12, \quad F=5.2, \quad P=0.023$ ). Further $($ at $\mathrm{Fz})$ there was a main effect of treatment $(\mathrm{df}=1.5$, $F-11.3, \quad P=0.02$ ). The main factor responsible was the reduced N1 amplitude to the rare nontarget on fenfluramine ( $P<0.05$, Fig. 1). Target N1 amplitude at Fz, which decreased only slightly on treatment (Fig. 3C,E), tended to correlate with DA levels $(0.7, P<0.06)$.

Subtraction of rare non-target from target components in the active task showed increased NI negativity on fenfluramine (placebo, +4.6, S.E.M. 4.0; fenfluramine, -6.4 , S.E.M. $2.7 \mu \mathrm{V}$ at Fz). The opposite was shown by subtraction of standards from rare non-targets (placebo - 2.7, S.E.M. 8.2; fenfluramine, +1.5, S.E.M. $5.4 \mu \mathrm{V}$ ). A two-way treatment (2) by stimulus (2) MANOVA showed no main effect but a significant interaction $(\mathrm{df}=$ 1.6, $F=8, P=0.03$; for subtraction of non-target, $t=+2.6$ and subtraction of standard, $t=-2.6$, $P<0.04)$. The latter measure was negatively correlated with DA levels $\left(-0.7, i^{2}<0.05\right)$.

Subtraction of low tone ('target') components obtained in the passive from the active task showed a smaller increase of negativity with treatment (placebo, - 2.2, S.E.M. 8.3; fenfluramine, -3.9 , S.E.M. $2.4 \mu \mathrm{V} ; \mathrm{df}=1,5, \quad F=3.7, \quad P=0.1$ ). But Fig. $3 \mathrm{G}$ shows the wide distribution of this distinct increase of negativity across all and particularly the more lateral sites.

P3 latency. Fenfluramine did not significantly affect P3 latency (Fig. 2), although 3 subjects with very long latencies showed marked decreases with

Fig. 3. Topographic maps of ERPs to targets obtained by 4-point inverse cubic interpolation from 7 scalp electrodes (Fz, Cz, Pz, F3, F4, P3, P4) applied to a $50 \times 50$ point matrix (Desmedt et al., 1987). Each map is labelled with subject number or mean, component (N1 or P3) and latency. A,B: single subject (04) maps show a rostrocaudal shift of midline N1 and P3 peak maxima with fenfluramine relative to placebo treatment (cf. Table III). Note also a normalization of P3 topography with restriction of peak positivity to parietal regions after fenfluramine. This was not observed in all subjects. C,D: single subject (03) maps show decreased frontal N1 negativity and increased, normalized P3 parietal positivity with fenfluramine treatment (cf. Figs. 1 and 2). This subject also shows a 200-ms reduction in P3 latency. E,F: maps of grand mean (GM) data ( $n, 6$, due to missing data) show decreased frontal N1 negativity and increased parietal P3 positivity after fenfluramine (cf. Figs. 1 and 2). G,H: difference maps obtained by subtracting passive (' $T$ ') from active (T) condition grand mean ERPs to targets. They show increased frontal Nd negativity and decreased parietal positivity after fenfluramine treatment. 
treatment (Fig. 4, right, Pz). There were no significant correlations with DA metabolism.

P3 amplitude. A 3-way ANOVA (as above) showed a main effect of tone $(\mathrm{df}=2.8, F=13.6$, $P=0.003$ ). This reflects the ERP peaks to the two rare and not to the standard stimuli (Fig. 2). There was a trend towards larger peaks at $\mathrm{Pz}$ to the rare stimuli after treatment $(\mathrm{df}=1,3, F=4.9, P=0.1$; e.g. Figs. 3D,F and 4). DA levels tended to be negatively correlated with the target waveform $(-0.63, P<0.09)$.

For $\mathrm{P} 3$ there was decreased positivity $(n=6$, $\mathrm{df}=2,4, F=6.2, P=0.059)$ after subtracting rare non-target from target (placebo; 6.1 S.E.M. 3.0; fenfluramine 1.8 S.E.M. 3.0) and standard from rare non-target waveforms (placebo, -3.2 S.E.M. 1.9; fenfluramine, -10.5 S.E.M. 4.1) in the active task.

After subtraction of passive from active task wave forms, target $\mathrm{P} 3$ amplitude at $\mathrm{Pz}$ was nearly halved in the fenfluramine condition (placebo, 21.9 S.E.M. 5.2; fenfluramine, 11.9, S.E.M. 2.6 $\mu \mathrm{V} ; \mathrm{df}=3,3, \quad F=8.3, \quad P=0.05 ; \quad$ Fig. $3 \mathrm{H})$. The effect is quantitatively but not qualitatively changed by taking late $\mathrm{P} 3$ peaks in 3 subjects into account. Subtracted P3 peaks to rare non-target and standard stimuli showed little change (respectively placebo/fenfluramine, $18.3 / 23.5$ and $5.0 / 7.6 \mu \mathrm{V})$. There were no correlations with urinary measures.

Slow wave components. For late SW positivity recorded at $\mathrm{Pz}$ there was a trend similar to that for the $\mathrm{P} 3$ component with positivity to the rare nontarget increasing in the fenfluramine condition but decreasing after subtraction of the ERPs obtained on the passive from those on the active task (rare non-target; +5.4, S.E.M. $6.4 ;-3.3$, S.E.M. 2.4 $\mu \mathrm{V})$. Neither NW nor SW responses showed any significant interaction or treatment effects or correlations with urinary measures.

\section{Lateral ERPs}

A small increase of $\mathrm{N} 1$ latencies $(+1-10 \mathrm{~ms})$ over the right hemisphere $\left(\mathrm{F}_{4}\right.$, Table $\left.\mathrm{V}\right)$ after fenfluramine treatment was not significant, but there was a tendency for a positive correlation between longer non-target latency on the right with DA
TABLE IV

Correlations between urinary monoamine measures and behavioral $/ E R P$ results

Pearson partial correlations taking age into account were sought in both treatment periods in 6 autistic children. Trends were only found with respect to decreasing DA or increasing utilization in the fenfluramine period. Only $\mathrm{Nd}$ and lateralized amplitude changes reached conventional $5 \%$ significance levels, but trends attaining ca. $10 \%$ levels are reported as an aid to insight into underlying mechanisms. Correlations for NA and other behavioral/ERP measures discussed in the text, were not significant, $P>0.11$. T, target; NT, non-target; R, right hemisphere; $\mathrm{RT}$, reaction time.

\begin{tabular}{|c|c|c|c|c|}
\hline \multirow[b]{2}{*}{ IQ } & \multicolumn{2}{|c|}{ DA level } & \multicolumn{2}{|c|}{$\begin{array}{l}H V A / D A / \\
\text { utilization }\end{array}$} \\
\hline & -0.64 & $P<0.08$ & & \\
\hline beta & 0.62 & $P<0.09$ & & \\
\hline RT & -0.64 & $P<0.08$ & & \\
\hline N1 lat. & & & +0.61 & $P<0.11$ \\
\hline N1 lat. (R) & & & +0.67 & $P<0.1$ \\
\hline (P3 lat. & & N.S. & & N.S.) \\
\hline N1 ampl. (T) & +0.7 & $P<0.06$ & & \\
\hline Nd ampl. (T-NT) & -0.7 & $P<0.05$ & & \\
\hline N1 ampl. (T) (R) & & & -0.8 & $P<0.02$ \\
\hline NW ampl. (NT) (R) & & & -0.8 & $P<0.02$ \\
\hline P3 ampl. (T) & -0.63 & $P<0.09$ & & \\
\hline P3 ampl. (NT) (R) & -0.8 & $P<0.03$ & +0.65 & $P<0.08$ \\
\hline
\end{tabular}

utilization $(0.67, P<0.1)$. P3 latencies were highly variable in both treatment conditions (Table $\mathrm{V}$ ).

The amplitude of target $\mathrm{N} 1$ and rare non-target NW components was larger over the left hemisphere $\left(F_{3}\right)$ in the placebo condition but larger over $F_{4}$, particularly after targets, during fenfluramine treatment (not significant, Table V). But for all 7 subjects the rare non-target NW amplitude became significantly larger over the right frontal area $\left(\mathrm{F}_{4}\right)$ in the fenfluramine condition $(\mathrm{df}=1,5, F=14.4, P=0.013$ : co-varied for age, regression, $F=14.9, \quad P=0.012 ; \quad P<0.02,2$-tail Wilcoxun). There was a similar but not-significant trend for target-N1. DA metabolism was negatively correlated with right hemisphere target-N1 and non-target-NW amplitude $(-0.8, P<0.02)$.

A right hemisphere $\left(\mathrm{P}_{4}\right)$ dominance for target $\mathrm{P} 3$ and SW components appears to be reduced in the fenfluramine condition, but this proved not significant $(\mathrm{df}=1,5, F=2.2, P<0.19)$. This may have been due to the large variation in the small 
TABLE V

Latency and amplitude (SEM) of lateralized ERP responses from autistic subjects on placebo and fenfluramine: $N 1$ and $N W$ from frontal $(F)$ and $P 3$ and $S W$ from parietal $(P)$ sites elicited by target $(T)$ and non-target $(N T)$ tones

Positive values represent longer latency or larger amplitude over right hemisphere, negative values represent larger values over left hemisphere.

\begin{tabular}{|c|c|c|c|c|c|c|c|c|c|}
\hline \multirow[t]{2}{*}{ Condition } & & \multicolumn{2}{|l|}{$N /(F)$} & \multicolumn{2}{|l|}{$N W(\boldsymbol{F})$} & \multicolumn{2}{|l|}{$P 3(P)$} & \multicolumn{2}{|l|}{$S W(P)$} \\
\hline & & $\bar{T}$ & $N-T$ & $\bar{T}$ & $N-T$ & $\bar{T}$ & $N-T$ & $\bar{T}$ & $N-T$ \\
\hline \multirow[t]{2}{*}{ Placebo } & latency & $+3.3(1.7)$ & $+4.6(5.3)$ & & & $+1.6(6.9)$ & $-19.9(33.1)$ & & \\
\hline & amplitude & $-1.6(3.4)$ & $-1.2(1.0)$ & $+1.5(4.1)$ & $-3.9(2.6)$ & $+5.3(2.8)$ & $-1.1(2.3)$ & $+3.1(2.5)$ & $+1.5(2.2)$ \\
\hline \multirow[t]{2}{*}{ Drug } & latency & $+2.1(2.4)$ & $+5.9(3.9)$ & & & $+1.1(43.7)$ & $+2.0(2.7)$ & & \\
\hline & amplitude & $+3.2(1.9)$ & $+0.4(0.9)$ & $+1.2(2.0)$ & $+3.2(2.8)^{*}$ & $-0.4(3.5)$ & $-0.5(2.5)$ & $+1.3(2.4)$ & $+2.7(1.7)$ \\
\hline
\end{tabular}

${ }^{*} P<0.05$.

samples. Normalization of the data after the method of McCarthy and Wood (1985) confirmed the results obtained for N1, P3, NW and SW, above (Table V).

For both rare stimuli P3 amplitude correlated with IQ $(0.9, P<0.03)$. The right hemisphere non-target P3 amplitude correlated with urinary measures (DA, $-0.8, P=0.03$; metabolism, 0.65 , $P<0.08)$.

\section{DISCUSSION}

The study showed that N1 amplitude decreased markedly but that P3 amplitude tended to increase to the rare non-target after fenfluramine treatment. The former represents a normalizing feature and the latter an impairment (Oades et al., 1988). Treatment reduced early negativity after both rare stimuli at left frontal sites and late positivity after targets at right parietal sites. ERP subtraction procedures (non-target from target, supported by passive from active task waveform) showed an increase of negativity after fenfluramine over the first $200 \mathrm{~ms}$ from frontal to parietal sites. This is suggestive of increased endogenous activity that may represent increased activation by or attention to the target (Hink et al., 1978). But rather than showing increased $\mathrm{P} 3$ positivity to a meaningful stimulus (Duncan-Johnson and Donchin, 1977), after subtraction procedures, target- $\mathrm{P} 3$ amplitude was reduced in the fenfluramine condition. DA metabolism was associated with midline target N1 and P3 amplitude changes, but correlated particularly with changes at lateral sites to both rare stimuli. The results will be discussed separately in the order they were presented.

Urine analysis. By comparison with data from normal healthy children, younger autistic subjects ( $<10$ years) showed a higher level of DA metabolism. As there is a decrease of HVA excretion with increasing age, the level in the 5-10-year age group of autistic children may be compared with that from normal children aged 1-3 years (Soldin, 1982). Fenfluramine treatment increased DA metabolism in both age groups to varying degrees, independent of age. This is consistent with its reported neuroleptic action (Rowland and Carlton, 1986). Increased DA metabolism and a drop in levels of NA was marked in the sub-group that provided ERP data. Changes were not significant in those unable to do the task. This suggests that autistic children with greater levels of cognitive function (and IQ) are more sensitive to the neuroleptic action of fenfluramine. A $60 \%$ decrease of blood 5-HT levels has been reported in these children. Individual values correlated with plasma levels of fenfluramine but not with changes of intellectual or social function (Badcock et al., 1987; Stern et al., in press).

Task performance. By comparison with agematched controls, increased reaction time in the fenfluramine condition can be regarded as a normalising trend (Oades et al., 1988). This with the low frequency of errors of commission would indi- 
cate that, unlike hyperkinetic children (Oades, 1987), impulsiveness is not a major factor in this group. Hyperkinetic children typically show lower beta values and improvement is associated with an increase. Indeed it suggests that the present group showed a good understanding of the requirements of the task. The markedly larger P3s elicited by the rare stimuli with respect to standards supports this contention.

We believe that an improvement of task performance was not primarily due to improved concentration. Rather a relaxation of criterion (beta) and fewer errors of omission suggest a small but genuine improvement in selective attention to and recognition of meaningful stimuli, where overselectivity is a problem (Hermelin and O'Connor, 1970; Rutter, 1983; Miyashita, 1985). While it may not be valid to emphasise this if stimuli are highly discriminable, it was our experience that despite the large frequency difference between tones this was not the case. Several subjects were unable to perform the discrimination. Our experience contrasts with that of Campbell et al. (1987) who used a slightly higher dose of fenfluramine for a shorter period. They found that treatment slowed discrimination learning.

There was a stronger relationship between DA levels and IQ and reaction time (both -0.64 , $P<0.08)$ than with beta $(-0.63, P<0.097)$ and omission errors $(+0.56, P<0.15)$. Although the associations are weak, this suggests that non-verbal IQ may be related to ACRT performance and the biological factors that modulate it. In autistic children a greater increase of DA utilization was found in those who functioned at higher levels (i.c. the ERP group) and within this group improved performance was related to DA metabolism (Table II). Ritvo et al. (1986) also found that the less retarded benefited more from fenfluramine.

Midline ERP distribution. For a group of subjects where organic dysfunction might be expected, it was necessary to see at which recording sites ERPs were maximal. The results qualify the subsequent analysis of potentials from $\mathrm{Fz}$ and $\mathrm{Pz}$. In adults $\mathrm{N} 1$ is usually maximal at frontal and P3 at parietal sites. Children may show more variability as a function of development. We found P3 to be maximal at $\mathrm{Pz}$ in age-matched normal children
(Oades et al., 1988). But while N1 was maximal at $\mathrm{Fz}$ for targets, it often peaked at $\mathrm{Pz}$ for rare non-targets.

Changes of topography for ERP maxima with treatment were associated more with the rare non-target. N1 maxima moved caudally and P3 maxima rostrally in the fenfluramine condition. The former is a normalizing trend, the latter is anomalous. $\mathrm{N} 1$ and $\mathrm{P} 3$ components elicited by the target moved caudally (cf. Table III, Fig. 3B).

Midline ERPs. N1 latencies were longer than usual (e.g. Couchesne et al., 1984, 1985). We cannot entirely explain this, but the contribution of endogenous components associated with stimulus processing, that also show a later onset than the exogenous response (e.g. Nd Hansen and I Iillyard, 1980; Nc Courchesne et al., 1986), may have been marked in a task that proved difficult for learning disabled children. This is supported by the reduced P3 amplitude, which, in normal subjects, is associated with increased task difficulty (Polich 1987).

A tendency for N1 and P3 latencies to increase, particularly to the non-targets, was noted. Interestingly 3 subjects with abnormally long target-P3 latencies, showed large decreases in the fenfluramine condition. Long P3 latencies have been related to discrimination difficulty in adults (Ford et al., 1982; Polich, 1987). Of the 3 measures that might be related to task performance (IQ, criterion-beta and misses), only the number of misses changed markedly in all 3 subjects (i.e. decreased). The tendency for N1 latencies to increase and target-P3 latencies to decrease can be regarded as a normalizing influence of fenfluramine (Oades et al., 1988).

The apparent reduction of $\mathrm{N} 1$ and the increase of P3 amplitude to targets might seem a beneficial effect of treatment. Target-P3 amplitudes of agematched healthy children were found to be twice as large as in autistic subjects (Oades et al., 1988), but subtraction of ERPs elicited by rare nontargets from targets in the active condition and subtraction of components elicited by the 'target' in the passive from those elicited in the active presentation tell a different story.

Subtraction of the rare non-target from the target should partial out the common effects of 
infrequent stimuli, apart from pitch. The increased negativity on fenfluramine points to an increased ability for separation of the two rare stimuli (Fig. 1). The decreased responsiveness on fenfluramine to the rare non-target constitutes an improvement at this early stage of information processing.

However, the improvement is not continued at the $\mathrm{P} 3$ level of information processing. While subtraction of the rare non-target yielded a non-significant decrease of positivity on fenfluramine, positivity was halved after subtraction of the waveform elicited by the 'target' in the passive presentation. Clearly fenfluramine did not facilitate the attribution of significance to the target as indexed by P3 amplitude. Although Pritchard et al. (1987) report the absence of P3 amplitude anomalies for 5 autistic subjects on a 2-stimulus visual 'oddball' task, Novick et al. (1980) and Niwa et al. (1983) found that autistic subjects showed a less marked P3 amplitude increase from frequent to rare tones. The relative increase of P3 amplitude after rare non-targets in our subjects might be seen as a facilitation of a non-optimal strategy for rare stimulus selection.

Differences should be noted in comparing our report with that of August et al. (1984). They recorded from $\mathrm{Cz}$ alone using different reference electrodes, the task consisted of only two tones and ERP amplitude measures concentrated on N1-P3 differences. Their main finding was that large baseline responses to frequency tones decreased on fenfluramine. We would agree that the main effects of treatment were on non-target stimuli, that a reduction of amplitude was attributable to processes index by $\mathrm{N} 1$ and $\mathrm{P} 3$ components and that changes in the fenfluramine condition were not obviously related to its effects on 5-HT.

Lateralized ERPs. One might expect, if fenfluramine were to benefit a "retarded group of children with a development disorder" (Ornitz, 1985), that an improvement would be associated with an increased lateralization of cerebral activity in the direction commonly seen in mature adults. In contrast autistic children (on placebo) seem to show more lateralization than their normal agematched counterparts (Oades et al., 1988). (This is reminiscent of Stevens and Milstein's (1970) re- port of a 'hyper-mature' EEG in autistic children). Negative components were slightly larger on the left (usual) and late positive components were larger on the right (less usual). Fenfluramine counteracted the lateralization tendencies for target-ERP amplitude in both early and late components.

It seems likely that activation in the left hemisphere (and midline) by rare non-target tones as indexed by the early NW (Born et al., 1986) was inhibited by fenfluramine. Speculatively, a reduction of late positivity recorded from mid-line sites and the right hemisphere with treatment might also have been beneficial, for Friedman et al. (1986) found excess late positivity correlated with attentional deviance in groups of children who were psychiatric or at risk for schizophrenia. But, noting that a few individuals showed marked behavioral improvement (e.g. subject 04; Stern et al., in press), one observes in Fig. $3 \mathrm{~A}$ and $\mathrm{B}$ a reduction of lateralized tendencies in favour of a normalization of rostrocaudal ERP amplitude distribution.

ERPs and DA utilization. We attribute reduced DA levels and increased DA metabolism to the neuroleptic effect of fenfluramine, but there was only a very small correlation between DA metabolism and N1 latency $(0.61, P<0.11)$. DA deficiency or neuroleptic treatment is widely reported to increase adult ERP latencies, particularly those occurring prior to P3 (Nakra et al., 1975; Rey et al., 1980; Schlor et al., 1985). In autistic children Martineau et al. (1985) found N1 latency increases associated with reduced HVA excretion after treatment. It is not easy to select a reason as to why the results differ as their study involved different treatment (vitamin $\mathrm{B} 6$ and magnesium), test paradigm (conditioning) and protocol.

DA levels were positively associated with target N1 changes but negatively with the increasingly similar amplitude elicited by the two non-targets. There was a stronger negative relationship between DA metabolism and reduced early negativity elicited by the rare stimuli over left frontal sites. Since normal young adult auditory reducers show high, while auditory augmenters show low urinary levels of HVA (Bruneau et al., 1986), the 
processing of exogenous features partly indexed by $\mathrm{N} 1$ amplitude may be associated with changes of DA activity.

Of the later components, attenuated right hemisphere non-target P3 was negatively correlated with DA metabolism. To a lesser extent target P3 amplitude was associated with DA levels. The changes are largely consistent with a normalization of function (Oades et al., 1988). But in so far as the early negative waves include endogenous components, later changes may be contingent on these rather than being a direct effect of treatment. This would seem to be more likely if frontal DA projections are more widespread and active than those to caudal sites (Oades and Halliday, 1987). The idea that increased DA activity promotes switching between channels for information processing (Oades, 1985) is consistent with improvement with treatment of processes indexed by N1, where autistic subjects are said to show cognitive rigidity (Rutter, 1983) and N1 has been associated with channel selection (Hillyard et al., 1978). But increased switching could be detrimental for processes indexed by P3 if they are more dependent on the attachment of stimulus associations than on foregoing $\mathrm{N} 1$ activity.

Conclusions. Our conclusions must be strongly qualified by the small size of our study group. With fenfluramine treatment there was mild improvement of intellectual function and discrimination performance in a small group of autistic children who were not strongly retarded. This may have been associated with the neuroleptic effects of treatment, but it was not associated with clear changes of ERP characteristics. At best ERP analysis indicated that improvement may follow increased latency and enhanced target-related difference negativity. Treatment favoured a less than optimal attention strategy where P3 amplitudes increased more to non-target than target stimuli.

\section{ACKNOWLEDGEMENTS}

This research was performed with financial assistance from the Apex Foundation, Channel 10 children's fund of South Australia and the Flinders University research budget. We are grateful for the use of laboratory facilities to Professor L.B. Geffen, research assistance from Mrs. J. Gotch, statistical assistance from Mr. N. Bluhm and table preparation by Ms. J. Dodwell and K. Holliday. We thank Dr. M. Wright and Mr. J. Altree-Williams for helpful advice and discussion.

\section{REFERENCES}

Algeri, S., Achilli, G., Calderini, G.. Perego, C., Ponzio, F. and Toffano, G. (1987) Age-related changes in metabolic responses to chronic dopaminergic and serotonergic systems of rats treated with reserpine. Neurobiol. Aging, 8: 61-66.

August, G.J., Raz, N., Papanicolau, A.C., Baird, T.D., Hirsh, S. and Hsu, L. (1984) Fenfluramine treatment in infantile autism. J. Nerv. Ment. Dis., 172: 604-612.

Badcock, N.R., Spence. J.G. and Stern. I..M. (1987) Blood serotonin levels in adults, autistic and non-autistic children with a comparison of different methodologies. Ann. Clin. Biochem., 24: 625634.

Born, J.. Fehm-Wolfsdorf, G., Lutzenberger, W., Voight, K.H. and Fehm, H. (1986) Vasopressin and electrophysiological signs of attention in man. Peptides, 7: 189-193.

Bruneau, N., Barthelemy, C., Jouve, J. and Lelord, G. (1986) Frontal auditory-evoked potential augmenting-reducing and urinary homovanillic acid. Neuropsychoblology, 16: 78-84.

Campbell, M., Deutsch, S.I., Perry, R., Wolsky, B.B. and Palij, M. (1986) Short-term efficacy of fenfluramine in hospitalized pre-school age autistic children: an open study. Psychopharmacol. Bull., 22: 141-145.

Campbell, M., Small, A.M., Palij, M., Perry, R., Polonsky, B.B., Lukashok, D. and Anderson, L.T. (1987) The efficacy and safety of fenfluramine in autistic children: preliminary analysis of a double-blind study. Psychopharmacol. Bull., 23: $123-127$.

Cohen, D.J., Caparulo, B.K., Shaywitz, B.A. and Bowers, M.B. (1977) Dopamine and serotonin metabolism in neuropsychiatrically disturbed children. Arch. Gen. Psychiat., 34: $545-550$.

Courchesne, E., Elmasian, R. and Yeung Courchesne, R. (1986) Electrophysiological correlates of cognitive processing $\mathrm{P} 3 \mathrm{~b}$ and $\mathrm{Ne}$ basic, clinical and developmental research. In A.M. Halliday, S.R. Butler and R. Paul (Eds.), A textbook of Clinical Neurophysiology; Wiley, London, pp. 645-676.

Courchesne, E., Kilman, B., Galambos, R. and Lincoln, A. (1984) Autism: processing of novel auditory information assessed by event-related potentials. EEG Clin. Neurophysiol., 59: 238-248.

Courchesne, E., Lincoln, A.J., Kilman, B.A. and Galambos, R. (1985) Event-related potential correlates of the processing of novel visual and auditory information in autism. $J$. Aut. Dev: Disord., 15: 55-76.

Damasio, A.R. (1984) Autism. Arch. Neurol., 41: 481. 
Desmedt, J.E., Nguyen, T.H. and Bourguet, M. (1987) Bitmapped color imaging of human cvoked potentials with reference to the $\mathrm{N} 20, \mathrm{P} 22, \mathrm{P} 27$ and N30 somatosensory repsonses. EEG Clin. Neurophysiol., 68: 1-19.

Duncan-Johnson, C.C. and Donchin, E. (1977) On quantifying surprise: the variation in event-related potentials with subjective probability. Psychophysiology, 14: 456-467.

Ford, J.M., Pfefferbaum, A. and Kopell, B.S. (1982) Elfects of perceptual and cognitive difficulty on P3 and RT in young and old adults. EEG Clin. Neurophysiol., 54: 311-321.

Frankel, F., Simmons, J., Fichter, M. and Freeman, B.J. (1984) Stimulus overselectivity in autistic and mentally retarded children, a research note. J. Child Psychol. Psychiatry, 25: $147-155$.

Friedman, D., Cornblatt, B., Vaughan, H. and Erlenmeyer-Kimling, L. (1986) Event-related potentials in children at risk for schizophrenia during two versions of the continuous performance test. Psychiat. Res., 18: 161-177.

Garnier, C., Comoy, E., Barthelemy, C., Leddet, I., Garreau, B., Muh, J. and Lelord, G. (1986) Dopamine-beta-hydroxylase (DBH) and homovanillic acid (HVA) in autistic children. J. Aut. Dev. Disord., 16: 23-29.

Gillberg, C. and Svennerholm, L. (1987) CSF monoamines in autistic syndromes and other pervasive developmental disorders of early childhood. Br. J. Psychiat., 151: 89-94.

Goodin, D., Squires, K., Henderson, B. and Starr, A. (1978) Age-related variations in evoked potentials to auditory stimulation in normal subjects. EEG Clin. Neurophysiol, 44: $447-458$

Halliday, R., Callaway, E. and Lynch, M. (1984) Age, stimulant drug and practice effects on P3 latency and concurrent reaction time. Ann. N.Y. Acad. Sci., 425: 357-361.

Hansen. J.C. and Hillyard. S.A. (1980) Endogenous brain potentials associated with selective auditory attention. $E E G$ Clin. Neurophysiol., 49: 277-290.

Hermelin, B. and O'Connor, N. (1970) Psychological Experiments with Autistic Children, Pergamon, Oxford.

Hillyard, S.A., Picton, T.W. and Regan. D. (1978) Sensation, perception and attention: analysis using ERPs. In E. Callaway, P. Tueting and S. Koslow, (Eds.), Event-related Brain Potentials in Man, Academic, London, pp. 223-321.

Hink, R.F., Fenton, W.H., Pfefferbaum, A., Tinklenberg, J.R. and Kopell, B.S. (1978) The distribution of attention across auditory input channels: an assessment using the human auditory potential. Psychophysiology, 15: 466-473.

Ho, H.H., Lockitch, G., Eaves, L. and Jacobson, B. (1986) Blood serotonin concentrations and fenfluramine therapy in autistic children. J. Pediatr., 108: 465-469.

Hoshino, Y., Yamamoto, T., Kaneko, M., Tachibana, R., Watanabe, M., Ono, Y. and Kumashiro, H. (1984) Blood serotonin and free tryptophan concentration in autistic children. Neuropsychobiology, 11: 22-27.

Invernizzi, R., Berettera, C., Garattini, S. Samanin, R. (1986) D- and L-isomers of fenfluramine differ markedly in their interaction with brain serotonin and catecholamines in the rat. Eur. J. Pharmacol., 120: 9-15.
Kanner, L. (1943) Autistic disturbances of affective contact. Nerv. Child, 2: 217-250.

Kopin, I.J. (1985) Catecholamine metabolism: basal aspects and clinical significance. Pharmacol. Rev., 37: 3333-364.

Lelord, G., Laffont, F., Jusseaume, P. and Stephant, J.L. (1973) Comparative study of conditioning of averaged evoked responses by coupling sound and light in normal and autistic children. Psychophysiology, 13: 81-85.

Martineau, J., Garreau, B. Barthelemy, C. and Lelord, G. (1984a) Evoked potentials and P 300 during sensory conditioning in autistic children. Ann. N.Y. Acad. Sci., 425: 362-369.

Martineau, J., Barthelemy, C., Garreau, B., Tanguay, P., Bruneau, N. and Lelord, G. (1984b) Relations entre les potentiels evoques auditifs (presence, amplitude) au cours du conditionnement sonlumiere et les taux de derives de la dopamine dans l'autisme de l'enfant. Rev. EEG Neurophysiol., 14, 139-148.

Martineau, J., Bathelemy, C.. Garreau, B. and Lelord, G. (1985) Vitamin B6, magnesium and combined B6-Mg: therapeutic effects in childhood autism. Biol. Psychiat., 20: $467-478$

McCarthy, G. and Donchin, E. (1981) A metric for thought: a comparison of $\mathrm{P} 300$ latency and reaction time. Science, 211: $77-80$.

McCarthy, G. and Wood, C.C. (1985) Scalp distributions of event-related potentials: an ambiguity associated with analysis of variance models. EEG Clin. Neurophysiol., 62: 203208.

Miyashita, T. (1985) Visual discrimination learning with variable irrelevant cues in autistic children. J. Aut. Dev. Disord., 15: $399-408$.

Nakra, B.R.S., Bond, A.J. and Lader, M.H. (1975) Comparative psychotropic effects of metaclopromide and prochlorperazine in normal subjects. J. Clin. Pharmacol, 17: 449454.

Niwa, S., Ohta, M. and Yamazaki, K. (1983) P 300 and stimulus evaluation process in autistic subjects. J. Aut. Dev. Disord., 13: 33-42.

Novick, B., Vaughan, H.G., Kurtzberg, D. and Simson, R. (1980) An electrophysiologic indication of auditory processing defects in autism. Psychiat. Res., 3: 107-14.

Oades, R.D. (1985) The role of noradrenaline in tuning and dopamine in switching between signals in the CNS. Neurosci. Biobehav. Rev., 9: 261-282.

Oades, R.D. (1987) Attention deficit disorder with hyperactivity $(\mathrm{ADDH})$ : the contribution of catecholaminergic activity. Prog. Neurobiol., 29: 365-391.

Oades, R.D. and Halliday, G.M. (1987) Ventral tegmental (A 10) system: neurobiology. 1. Anatomy and Connectivity. Brain Res. Rev., 12: 117-165.

Oades, R.D., Walker, M.K., Geffen, L.B. and Stern, L.M. (1988) Event-related potentials in autistic and healthy children on an auditory choice reaction time task. Int. J. Psychophysiol., 6: 25-37. 
Ornitz, E.M. (1985) Neurophysiology of infantile autism. J. Am. Acad. Child Psychiat., 24: 251-262.

Ornitz, E.M., Tanguay, P.E., Lee, J.C.M., Ritvo, E.R., Sivertsen, B. and Wilson, C. (1972) The effects of stimulus interval on the auditory evoked response during sleep in autistic children. J. Aut. Child. Schizophr., 2: 140-150.

Pfefferbaum, A., Ford, J.M., Wenegrat, B.G., Roth, W.T. and Kopell, B.S. (1984) Clinical application of the P3 component of event-related potentials. EEG Clin. Neurophysiol., 59: 85-103.

Polich, J. (1987) Task difficulty, probability and inter-stimulus interval as determinants of P300 from auditory stimuli. EEG Clin. Neurophysiol., 68: 311-320.

Pritchard, W.S., Raz, N. and August, G.J. (1987) Visual augmenting/reducing and $\mathrm{P} 300$ in autistic children. J. Aut. Dev. Disord.. 17: 231-242.

Rey, A.C., Buchsbaum, M.S. and Post, R.M. (1980) Apomorphine, haloperidol and the averaged evoked potentials in normal human volunteers. Commun. Psychopharmacol., 4: 327-334.

Ritvo, E.R., Freeman, B.J., Geller, E. and Yuweiler, A. (1983) Effects of fenfluramine on 14 outpatients with the syndrome of autism. J. Am. Acad. Child Psychiat., 22: 549-558.

Ritvo, E.R., Freeman, B.J., Yuwiler, A., Geller, G., Schroth, P., Yokota, A., Mason-Brothers, A., August, G.J., Klykylo, W., Leventhal, B., Lewis, M.D., Piggott, L., Realmuto, G., Stubbs, E.G. and Umansky, R. (1986) Fenfluramine treatment of autism: UCLA collaborative study of 81 patients at nine medical centers. Psychopharmacol. Bull., 22: 133140.

Roth, R., Murrin, L. and Walters, J. (1976) Central dopaminergic neurons: effects of alterations in impulse flow on the accumulation of dihydroxyphenylacetic acid. Eur. $J$. Pharmacol., 36: 163-171.

Rowland, N.E. and Carlton, J. (1986) Neurobiology of an anorectic drug: fenfluramine. Prog. Neurobiol., 27: 13-62.

Rutter. M. (1983) Cognitive deficits in the pathogenesis of autism. J. Child Psychol. Psychiat., 24: 513-531.
Saletu, S., Saletu, M., Itil, T.M. and Simeon, J. (1975) Brain function analysis in childhood psychosis: evoked repsonses. Clin. Electroencephalog., 6: 44-53.

Schain, R.J. and Freedman, D.X. (1961) Study on 5-hydroxyindole metabolism in autistic and mentally retarded children J. Pediatr, 58: 315-320.

Schlor, K-H., Moises, H.W., Haas, S. and Rieger, H. (1985; Schizophrenia, psychoticism, neuroleptics and auditory evoked potentials. Pharmacopsychiatry, 18: 283-296.

Small, J.G., DeMeyer, M.K. and Kendall, J.K. (1969) Experience with response averaging in autistic children. $E E G$ Clin. Neurophysiol., 26: 112-113.

Small, J., De Meyer, M.K. and Milstein, V. (1971) CNV responses of autistic and normal children. J. Aut. Child. Schizophr., 1: 215-231.

Smedes, F., Kraak, J.C. and Poppe, H. (1982) Simple and fast solvent extraction system for selective and quantitative isolation of adrenaline, noradrenaline and dopamine from plasma and urine. $J$. Chromatogr., 231: 25-39.

Soldin, S.J. (1982) HPLC applications in a children's hospital. Adv. Chromatogr., 20: 149-166.

Stern, L.M., Walker, M.K. Sawyer, M.G., Oades, R.D., Badcock, N.R. and Spence, J.G. An in depth trial of fenfluramine in autism. J. Child Psychol. Psychiat., in press.

Stevens, J.K. and Milstein, V. (1970) Severe psychiatric disorders of childhood: electroencephalogram and clinical correlates. Am. J. Disabled Child, 120: 182-192.

Stubbs, E.G., Budden, S.S., Jackson, R.H., Terdal, L.G. and Ritvo, E.R. (1986) Effects of fenfluramine on eight outpatients with the syndrome of autism. Dev. Med. Child Neurol., 28: 229-235.

Westerink, B.H.C. and Kikkert, R.J. (1986) Effect of various centrally acting drugs on the efflux of dopamine metabolites from the rat brain. J. Neurochem., 46: 1145-1152.

Young, J.G., Kavanagh, M., Anderson. G.M., Shaywitz, B.A. and Cohen, D.J. (1982) Clinical neurochemistry of autism and associated disorders. J. Aut. Dev. Disord. 12: 147-165. 